\title{
Use of Orbital Images and Interpolation Techniques: Climate Monitoring in Permanent Preservation Area (Humid Subtropical Climate)
}

\author{
Aparecido Ribeiro de Andrade ${ }^{*}{ }^{(0)}$, Marcos Aurelio Pelegrina ${ }^{2}$, Juliane Bereze ${ }^{1}$, \\ João Anésio Bednarz', Bruno Henrique Costa Toledo1,2 \\ ${ }^{1}$ Department of the Geography, Climatology and Environmental Analysis Laboratory, Universidade Estadual do Centro-Oeste, \\ Unicentro, LACLIAM, Guarapuava, Paraná, Brazil \\ ${ }^{2}$ Department of the Geography, Geoprocessing Laboratory, LABGEO, Universidade Estadual do Centro-Oeste, Unicentro, \\ Guarapuava, Paraná, Brazil \\ Email: *arandrade@unicentro.br
}

How to cite this paper: de Andrade, A.R., Pelegrina, M.A., Bereze, J., Bednarz, J.A. and Toledo, B.H.C. (2020) Use of Orbital Images and Interpolation Techniques: Climate Monitoring in Permanent Preservation Area (Humid Subtropical Climate). Journal of Geographic Information System, 12, 560-578.

https://doi.org/10.4236/jgis.2020.126033

Received: September 23, 2020

Accepted: November 16, 2020

Published: November 19, 2020

Copyright $\odot 2020$ by author(s) and Scientific Research Publishing Inc. This work is licensed under the Creative Commons Attribution International License (CC BY 4.0).

http://creativecommons.org/licenses/by/4.0/ (c) (i) Open Access

\begin{abstract}
The present work sought to demonstrate the importance using geoprocessing techniques and methodologies in the identification and analysis of the temporal and spatial distribution of air temperature. Therefore, an environment with difficulties for systematic monitoring of climatic elements was selected in the Serra da Esperançaárea, southern region of the State of Paraná. Two methodologies established in geoprocessing were used: the first deals with the interpretation of orbital images and the second makes reference to the interpolation of surface data. These methodologies, used in an integrated way, made it possible to know the relationship between the spatial and temporal distribution of air temperature with vegetation and the terrain altimetry. The air temperature data were monitored at 4 (four) points, following the contours of the federal highway that passes through the study area. Satellite images were obtained of July 26th, 2015 and January 18th, 2016, representing winter and summer southern conditions. The results indicated that this relationship exists and that in the absence of absolute data monitored at conventional collection points, geostatistics techniques allow good estimation. Moreover, this methodology can be used to control land use change in permanent preservation areas.
\end{abstract}

\section{Keywords}

Air Temperature, Topoclimate, Geostatistics 


\section{Introduction}

Climatology needs geostatistical data to validate its analysis. Therefore, geoprocessing techniques are important tools in this process. This form of interpretation of geographical facts is associated with the methodological framework of the so-called Positivist Geography. Even though having undergone several criticisms in the last 30 years, it persists as an effective methodology in climatological studies.

These studies emphasize the physical relationship between relief, vegetation, temperature and air humidity in an unequivocal manner and a belief in climatological science taken as common sense. In this way the visualization of this relationship using maps and graphs is interesting to be represented and it is in this aspect that geoprocessing fits perfectly in the climate analysis.

Cartographic representation, most often uses geoprocessing technique, aims to make the importance of the phenomenon more evident. This usually occurs if there is coherence between the text of a survey and the maps used.

In spite of this, there is no regular literacy mapping or training in Brazilian elementary education, so the interpretation of maps is a difficult task. This happens even at the highest levels of academical training (doctorate) because graphic representations are not part of daily life. Curricular contents and activities are dispersed and do not facilitate the formation of a researcher to produce and analyze these representations with quality [1].

This representation, although extremely important for Geography and its areas of expertise (Climatology, for example), often becomes a mere addition of totally fragmented visual elements without any real usefulness to goals of the research developed. This is a general problem, but in climatology it is amplified because the spatialization of climatic phenomena in a particular area and in a specific period is usually the central focus of analysis.

Reference [1] concludes his work with an enquiry: How to graphically represent essences of such complex relationships? The author points out that only the search for new idealizations and realizations of Cartography can answer this question and this is the challenge of those who study the climate(s) all over the planet. Geography, with cartography and geoprocessing as a support base, can and must close this gap.

One of the main problems of graphical representation in climatology is the difficulty of monitoring data, culminating in problems of geostatistic analysis. In this sense, [2] proposes a methodology to graphically represent air temperature and relative humidity in places that are difficult to monitor. The idea proposed by the authors is based on linear regression techniques that aim to estimate meteorological data, considering the geographical location (latitude/longitude) and the altitude of the collection points. This procedure has proven to be efficient to regionalize the air relative humidity in the San Francisco River Valley, eastern range of the Ecuadorian Andes.

In this study, historical data from six collection points and high-resolution sa- 
tellite images were used. In the end, both the graphs with the statistical representativeness of the model, as well as maps of the distribution of air humidity related to land-use (vegetation), proved to be efficient to know and predict the variability of this climatic element.

An interesting methodological maturity can be seen in this work, combining mathematical data with spatial representation of the results obtained. The maps, graphs and tables were elaborated using a Geographic Information System (GIS), which provided consistent results regarding the visual representation of a geographical variable, more specifically climate (relative air humidity). This type of work values the interaction of Climatology with Geoprocessing techniques.

Work such as this demonstrates the importance of knowing the reciprocal relationships between climatic variability and variation in altimetry levels in the earth's surface, aiming at the conservation and maintenance of one of the richest natural resources to our planet vegetation. This is even more relevant in endemic biomes, such as the Araucaria Angustifolia core area, predominant in the altimontane regions of the southern east of Brazillian territory.

Another work that proves this reasoning is that of [3], in which they stress the importance of using Remote Sensing (orbital images) to identify the floristic composition in land use for different areas of the planet. The work aimed to prove the efficiency of the remote sensing technique and for this purpose, made a comparison between various methodologies used to obtain the Vegetation Index. Consulting several authors who proposed concepts and procedures for this methodology, it was possible to notice that some indices are more sensitive than others. The NDVI (normalized difference vegetation index) and RVI (Ratio Vegetation Index), for example, were more sensitive than the NDVI (green normalized difference vegetation index) and WDRVI (wide-dynamic-range vegetation index).

Besides, the NDVI can be considered one of the most widely used indexes for monitoring and surveying vegetation, as well as SAVI (soil adjusted vegetation index). The difference is that the first highlights the background soil, while the second tends to minimize this effect. NDVI can also be considered a good biomass evaluator and has a good correlation with the moisture content of the plant.

Therefore, a common problem when using orbital image analysis to obtain the spatialization of different types of land use is the choice of the most appropriate vegetation index. Some indexes are more accurate to identify vegetation, highlight exposed soil, as is the case with the NDVI, but end up underestimating the other types of use. The SAVI, on the other hand, values bare soil but underestimates the rest. NSWI (Severe Weather Data Inventory) is also another index that is widely used, but which highlights water (liquid surface) to the detriment of other aspects.

In an attempt to address this lack of accuracy of a particular methodology, [4] have used a composition of the NDVI, NDWI and NDBI index associated with 
RGB channels, obtaining contrasts as an effective classification tool in the separation of water, clouds, built area, exposed soil and water bodies. Except for the problems encountered with clouds, the model has become very accurate, achieving close to $100 \%$ correlations for actual land use.

It is then realized that the use of geotechnology with the most distinct methodologies becomes relevant in studies aimed at understanding the climate reality of the place, especially when this reality has a very close relationship with land use and surface topography. In this sense, remote sensing data, associated with the monitoring of temperature and relative humidity can be an important tool for the planning and monitoring of areas with restricted use, such as permanent preservation areas and ecological parks.

In areas of permanent preservation, it is interesting to understand the process of maintenance and modification of the quantity and variety of existing floristic species. Usually, the research directed to this area does not take into consideration the current, past or future climatic conditions, but simply seek to identify the spatial and temporal variability of the local flora

The studies such as that carried out by [5], therefore, demonstrate how geoprocessing can easily identify floristic variability over a given period of time. In this study, the authors analyzed the land cover in Yacambú National Park, located in Lara, Venezuela, using the fragmented index to find out whether the agricultural frontier surrounding the research area influenced the changes of the park's vegetation structure from 2000 to 2008 . The authors used remote sensing techniques to investigate possible environmental changes in the area, which proved to be very efficient in the process, as they found considerable levels of fragmentation. This analysis was more significant to understand the proportion of agricultural areas bordering the park that changed over time.

Although this study did not consider climate conditions as an actor in the process, it is known that it is not possible to dissociate the influence of climate and forest dynamics, especially in protected areas. Several studies have already demonstrated this relationship [6] [7] [8] and [9].

The area of the present study becomes an interesting object of research when considering this relationship, since its typical mountain climate, with high thermopluviometric variability, both on a seasonal and daily scale, is placed as a limit to the phytosociological evolution. So much so that the typical vegetation of the region (Araucaria Angustifolia) is an endemic species and its dispersion is very restricted, practically limiting itself to the South region of Brazil and this limitation is totally associated to geographical factors (climate, relief and soil).

Some studies have already addressed this specificity of the climate at central southern region of Paraná [10] [11] and [12], region where the evaluated study area is located, as shown in Figure 1. All these authors demonstrated the climatic characteristics of the region and emphasized the incontestable relationship between climate, relief and vegetation, permeated by atmospheric dynamics, i.e., the topographic assumption also influenced by the acting air masses. 


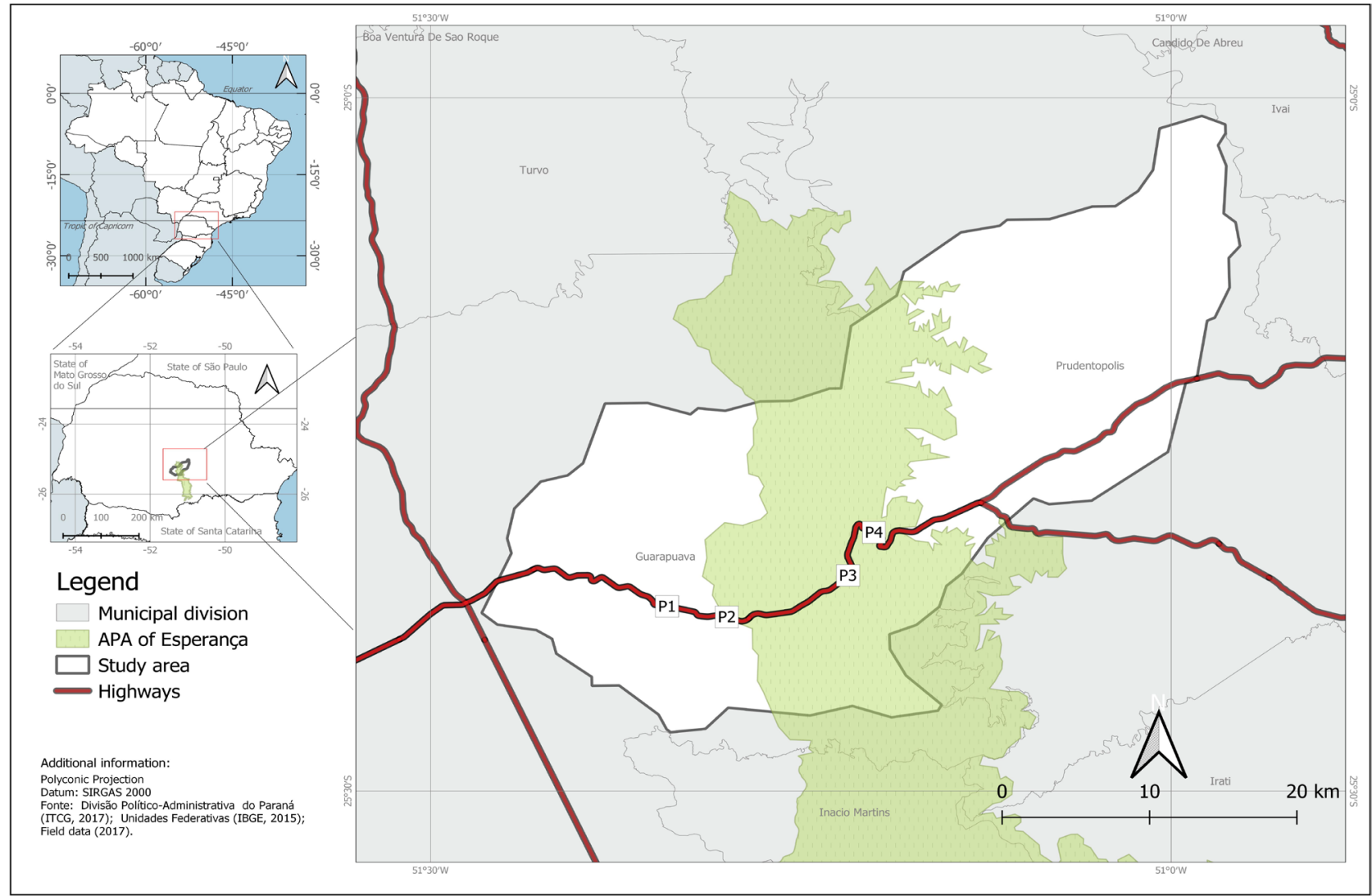

Figure 1. Location of the study area and collect points.

Thus, the present work seeks to demonstrate the importance of knowing, monitoring and predicting the spatial and temporal dynamics of meteorological elements at the topoclimatic scale. In this sense, they are considered mainly those that occur in places with high climatic variability and with the predominance of endemic vegetation in an area of permanent preservation, defined as a priority for environmental conservation and maintenance.

For this purpose, the use of Geoprocessing techniques is important and this can be demonstrated from the interpolation of available data, seeking to estimate the air temperature throughout the study area based on restricted collection points. Furthermore, the delimitation of the type of land use, specifically the density of vegetation, may indicate how air temperature is associated with forest distribution in study area.

\section{Materials and Methods}

\subsection{Investigation Area}

The study area is within the Serra da Esperança Permanent Preservation Area (Figure 1), specifically in the northern region sector. The county (Guarapuava and Prudentópolis) were selected because they are located at very variable altitudes (from $1200 \mathrm{~m}$ to $700 \mathrm{~m}$ ) and have highly specific geomorphological features, i.e. close to the border between the second and third plateaus of Paraná, in 
the area known as Serra da Esperança. Furthermore, Guarapuava is the largest county in Paraná and is located in a flattened area on the reverse side of the cuesta da Esperança, while Prudentópolis is in a steeper area and on the front of the mountain, which defines a topoclimatic approach scale.

Four (4) collection points have been installed on the transect of the Serra da Esperança scarp, between Guarapuava and Prudentópolis, following the outlines of BR 277 (Figure 1). For the installation of these points the altitude was taken into consideration. The equipment for monitoring the temperature data was installed and programmed to be collected every hour at each of the points.

The points were identified as P1 $(1060 \mathrm{~m}), \mathrm{P} 2(1211 \mathrm{~m}), \mathrm{P} 3(906 \mathrm{~m})$ and P4 $(705 \mathrm{~m})$. In each of these points a mini shelter was installed containing a temperature sensor attached with a data-logger that collects data in the interval of 60 minutes, that is, hourly with storage capacity for 333 days, of the PERCEPTEC brand, model DHT2000, with an accuracy of $0.5^{\circ} \mathrm{C}$, which stored air temperature data.

It is interesting to note that Point P1 is not necessarily within the area of APA da Serra da Esperança, but is important as an altitude control to validate the methodology used in data prediction

\subsection{Collection and Organization of Meteorological Data}

Hourly data were collected from June 1th of 2014 to July 31th of 2015, which were classified according to the hydrological year criteria. Later, the data were organized in spreadsheets, tabulated and validated through some statistical parameters, such asmediansimple arithmetic Equation (1), standard deviation Equation (2) and simple linear correlation of the Pearson Equation (3):

$$
\begin{gathered}
\frac{\sum\left(x_{i}\right)}{N_{i}} \\
\sqrt{\frac{\sum\left(x_{i}-x^{2}\right)}{N-1}} \\
r=\frac{1}{n-1} \sum\left(\frac{x i-\bar{x}}{S x}\right)\left(\frac{y i-\bar{y}}{S y}\right)
\end{gathered}
$$

All the calculations were made using the Microsoft Excel 2010 spreadsheet. It aimed simply to validate the data from the point of view of some mathematical error in their collection and organization.

\subsection{Geoprocesses and Thematic Maps}

The altimetric variation of the study area was elaborated from the raster data acquired by the INPE-TOPODATA database. Then it was possible to obtain the Digital Elevation Model with 30 meters resolution, from which the hypsometry of the terrain was elaborated (Figure 2). The altitude range between the lowest $(504 \mathrm{~m})$ and highest $(1331 \mathrm{~m})$ point demonstrates the importance of the study 
area for climate analysis, especially those aimed at the interaction between climate, relief and vegetation. The software used for data production and manipulation was ArcGIS 10.2.

The same cartographic base was used to obtain vegetation indexes and land use maps. However, satellite images from LandSat 8 July 7th 2015 and January 18th 2016 covering the study area were also analysed. These images were obtained from INPE (National Institute for Space Research) geomorphometric database.

From these images, the NDVI (Normalized Difference Vegetation Index) was calculated, which is a vegetation index used to highlight this target. It has the advantage of reducing many forms and noises such as lighting differences and cloud shadows. To obtain such an index is used Equation (4):

$$
\mathrm{NDVI}=\frac{(\rho \mathrm{ivp}-\rho \mathrm{vm})}{(\rho \mathrm{ivp}+\rho \mathrm{vm})}
$$

In this equation, for $\rho$ ivp we have the near-infrared reflectance, and $\rho \mathrm{vm}$ the red reflectance.

Another index calculated was the NDWI (Normalized Difference Water Index), which is an equation developed to highlight water bodies and eliminate the influence of soil on vegetation. It has been done using the Equation (5).

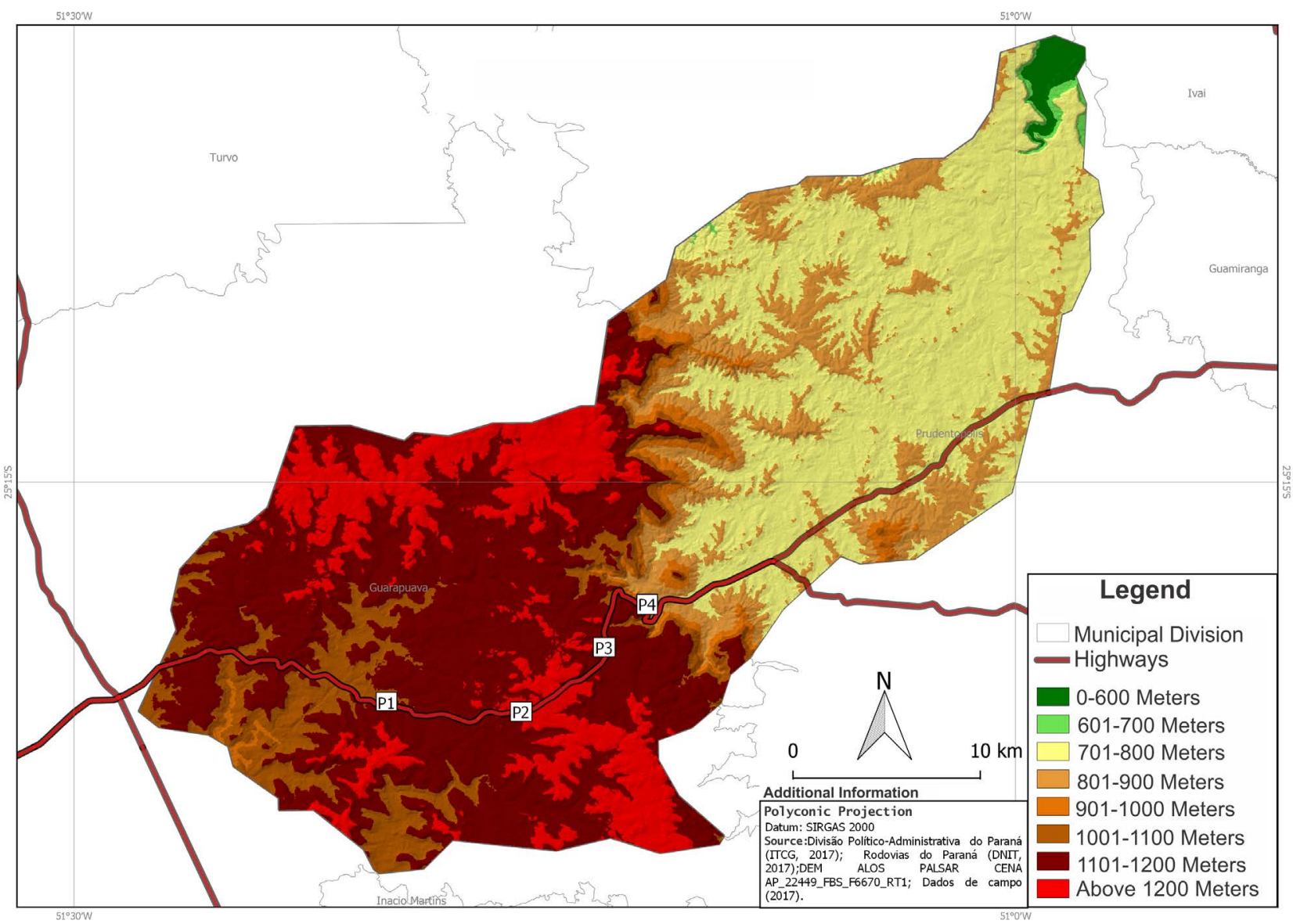

Figure 2. Hypsometric map of the study area and data collection points. 


$$
\mathrm{NDWI}=\frac{(\rho \mathrm{dv}-\rho \mathrm{ivp})}{(\rho \mathrm{vd}+\rho \mathrm{ivp})}
$$

at $\rho$ ivp is the near-infrared reflectance, and $\rho \mathrm{dv}$ is the green-band reflectance. All these calculations were performed as well in ArcGIS (Academic license), with version 10.2, generating maps with the spatialization of the results.

In order to draw up the interpolation maps of air temperatures, the samples collected in the field were used, in which the data were tabulated according to the methodology used by [2]. This methodology uses the Inverse of Weighted Distance method supported by Equation (6):

$$
T_{\text {Det }}=T_{\text {month }}+\left(\Gamma \cdot\left(Z_{x y}-Z_{\text {Det }}\right)\right)
$$

and

$$
T_{x y}=T_{\text {Det }}+\left(\Gamma \cdot\left(Z_{x y}-Z_{\text {Det }}\right)\right)
$$

where $T_{\text {Det }}$ is the average monthly base level temperature $\left[{ }^{\circ} \mathrm{C}\right]$ of the land-use unit, $Z_{\text {Det }}$ the detrending level [here $1000 \mathrm{~m}$ asl], $T_{\text {month }}$ is the average monthly temperature $\left[{ }^{\circ} \mathrm{C}\right], \Gamma$ the slope (= altitudinal gradient), $T_{x y}$ is the monthly temperature $\left[{ }^{\circ} \mathrm{C}\right]$ at position $(\mathrm{x}, \mathrm{y})$, and $Z_{x y}$ is the altitude [m asl] at position $(\mathrm{x}, \mathrm{y})$.

After the interpolation two images from the geomorphometric database of INPE (National Institute for Space Research), project TOPODATA (25S525ZN and 25S51_ZN) from which the study area was cut out were used.

Possible inconsistencies were also corrected through the fault filling process and transformed into 16 bits and the values of the rounded altitudes. After these the process of mapping the isotherms was carried out, through the algebra of maps applying following the method: interpolation of the inverse of the distance plus the constant of -0.0066 times the elevation (topodata) less median of the altitudes (986 meters).

Geoprocesses and the representation of spatial distribution of the data (maximum and minimum isotherms) used the IBGE (Brazilian Institute of Geography and Statistics, 2010) and TOPODATA (INPE) cartographic basis. All maps were executed using the ArcGIS software (Academic license) version 10.2, elaborated through the SIRGAS 2000 Reference System and Geographic Coordinates System. For space optimization and better understanding of climate data a cartographic generalization was made and the technical information was deleted from the figures presented in the discussing of results.

\subsection{Correlations NDVI and NDWI whit Maximum and Minimum Temperatures}

For the analysis of results between NDVI, NDWI, TEMP MAX and TEMP MIN, geographical weighted regression (GWR) was used. GWR aims to identify spatial heterogeneities in georeferenced data regression models [13]. According to [14] GWR can be expressed by the following Equation (7):

$$
y_{i}=\beta_{0\left(u_{i}, v_{i}\right)}+\sum \beta_{j}\left(u_{i}, v_{i}\right) x_{i j}+\varepsilon_{i}
$$

$y_{i}$ is equivalent to the result at the location of the coordinates, represented by 
$\left(u_{(i)}, v_{i}\right), \beta_{0}$ e $\beta_{(j)}$ represent the interception of the local estimate with effect of the variable $j$ for the location $i$. Locations near $i$ have a stronger influence on the estimate of $\beta_{(j)}\left(u_{i}, v_{i}\right)$, than values far from $i$. In the GWR model, estimates of localized parameters can be obtained for any location, which in turn allows the creation of a map showing a continuous surface of parameter values and an examination of the spatial variability of these parameters according [14].

The GWR was performed from 10,000 points, extracted at random, considering the pixel values of the adjusted temperature and the values of NDVI and NDWI.

\section{Results and Discussion}

At first moment, seeking to identify the differences in land use, maps showing this landscape element were analyzed (Figure 3 and Figure 4). These two maps sought to compare land use in different seasons. Thus, Figure 3 represents the predominant land use in the winter season (July 26th, 2015). As for Figure 4 represents this spatialization in summer period (January 18th, 2016).

When comparing Figure 3 and Figure 4 it can be seen that there are no significant differences between the types of use, considering their proportionality to the total area. However, some types of use differ from one season to another, and it is possible to notice this fact when analyzing their growth and/or decrease in the two seasons.

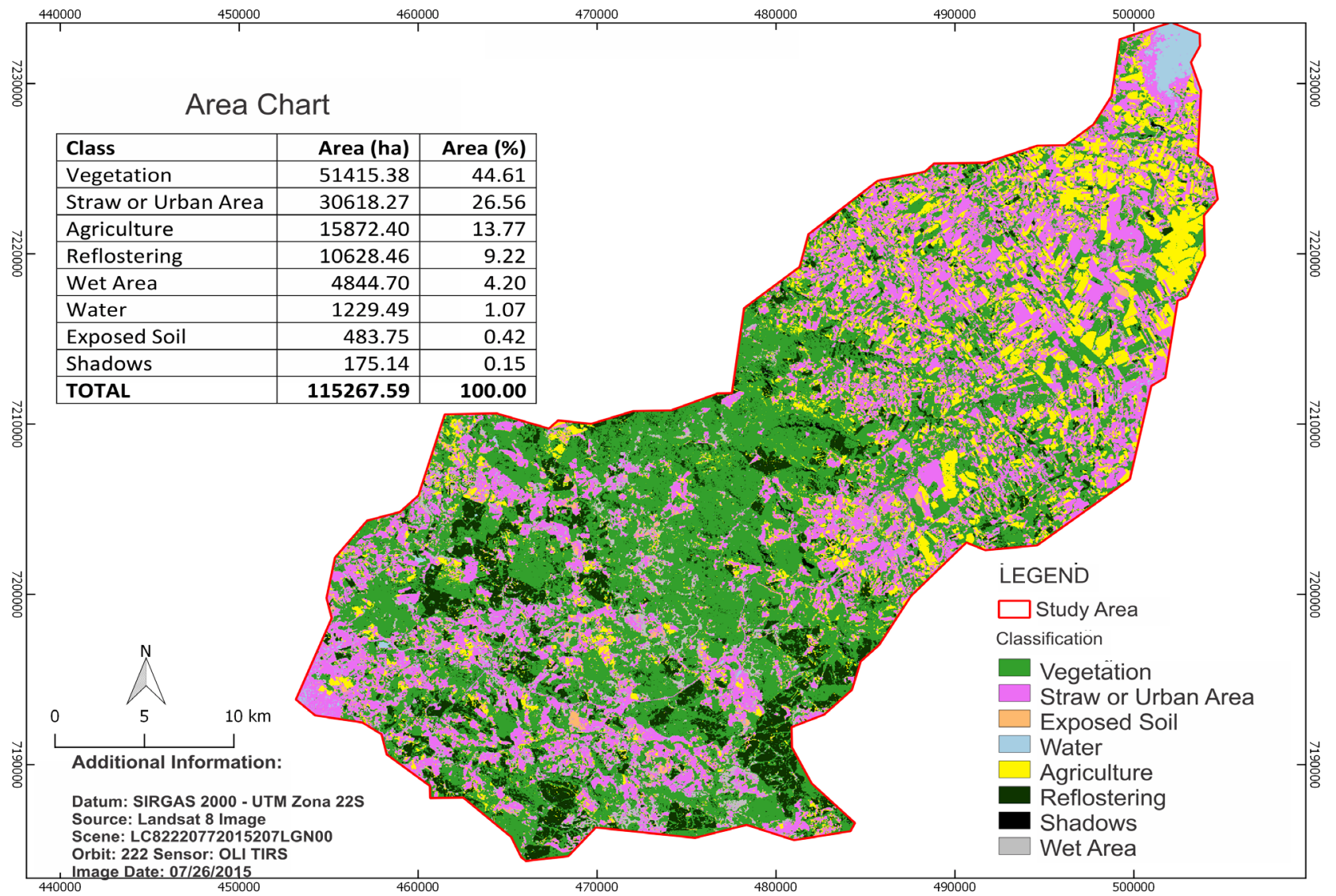

Figure 3. Land use Map on July 26th, 2015. 


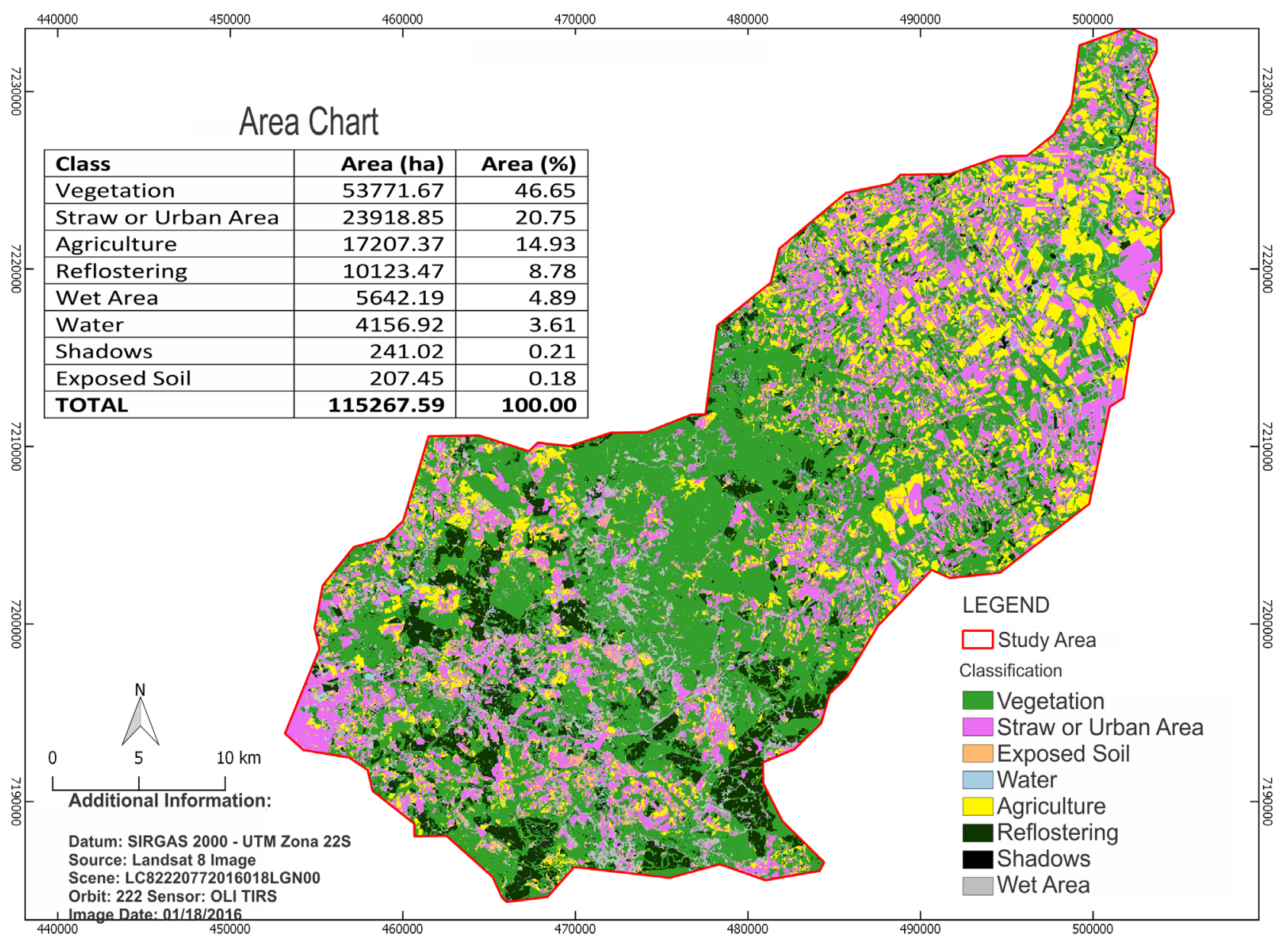

Figure 4. Land use Map on January 18th, 2016.

Reviewing at the area table it can be seen that vegetation it remains practically unchanged. The area of haystack/urban area varies a bit more (from $26.56 \%$ in winter to 20.75 in summer), which explain a higher concentration of haystack in winter, due to a big predominance of areas with decaying plant matter in that period (between harvests and falling leaves of the trees). In the same way, the area of exposed soil also increases in winter (from $0.18 \%$ to $0.41 \%$ ), which is explained by the decrease in arable land. Another type of use that changes is water/clouds, but this is concentrated in the northeast sector, due to the higher incidence of clouds in that location during the winter.

Thus, variations in the type of use do not vary significantly and the differences found are exclusively associated with weather conditions (clouds) and agricultural management (haystack and agriculture). This sets out that agricultural activities and the phenological cycle of vegetation are the only elements of the landscape that have changed seasonally, i.e. the region is stable, at least on this scale of analysis.

Figure 5 and Figure 6 represent the result of the NDVI calculation for July 26th, 2015 and January 18th, 2016 in the study area. There is a clear similarity between the two periods, i.e. this index identifies hardly any change between summer 
and winter, except in a small portion northeast of the area, explained by the high cloud concentration on that day, as already shown in Figure 3 and Figure 4. This concentration induces the NDVI to associate the clouds with lack of vegetation.

When comparing the two images (Figure 5 and Figure 6) and associating the forest characteristics with the air temperature, a slight decrease in the temperature in winter can be noticed, which is normal, due to the fact that the values of this element of the climate are obviously lower in the winter season. Apart from this, no more significant changes can be noticed. However, it should be noted that the NDVI shows a higher concentration of forest in the central region of the study area, which also leads one to deduce that milder surface temperatures occur there, both in summer and winter.

Even if there is a difference between surface temperature and air temperature, some works [15] and [16] indicate that there is a good correlation between one measure and another, although the response is not immediate and depending on the ground cover, this process can take several hours to occur.

However, the NDVI is a more general index that simply considers the greater or lesser concentration of vegetated areas. It conceives and still overestimates the lack of vegetation, because it considers any interference in environment (clouds, for example) as non-vegetated areas. In this sense, its analysis should be focused on forest density.

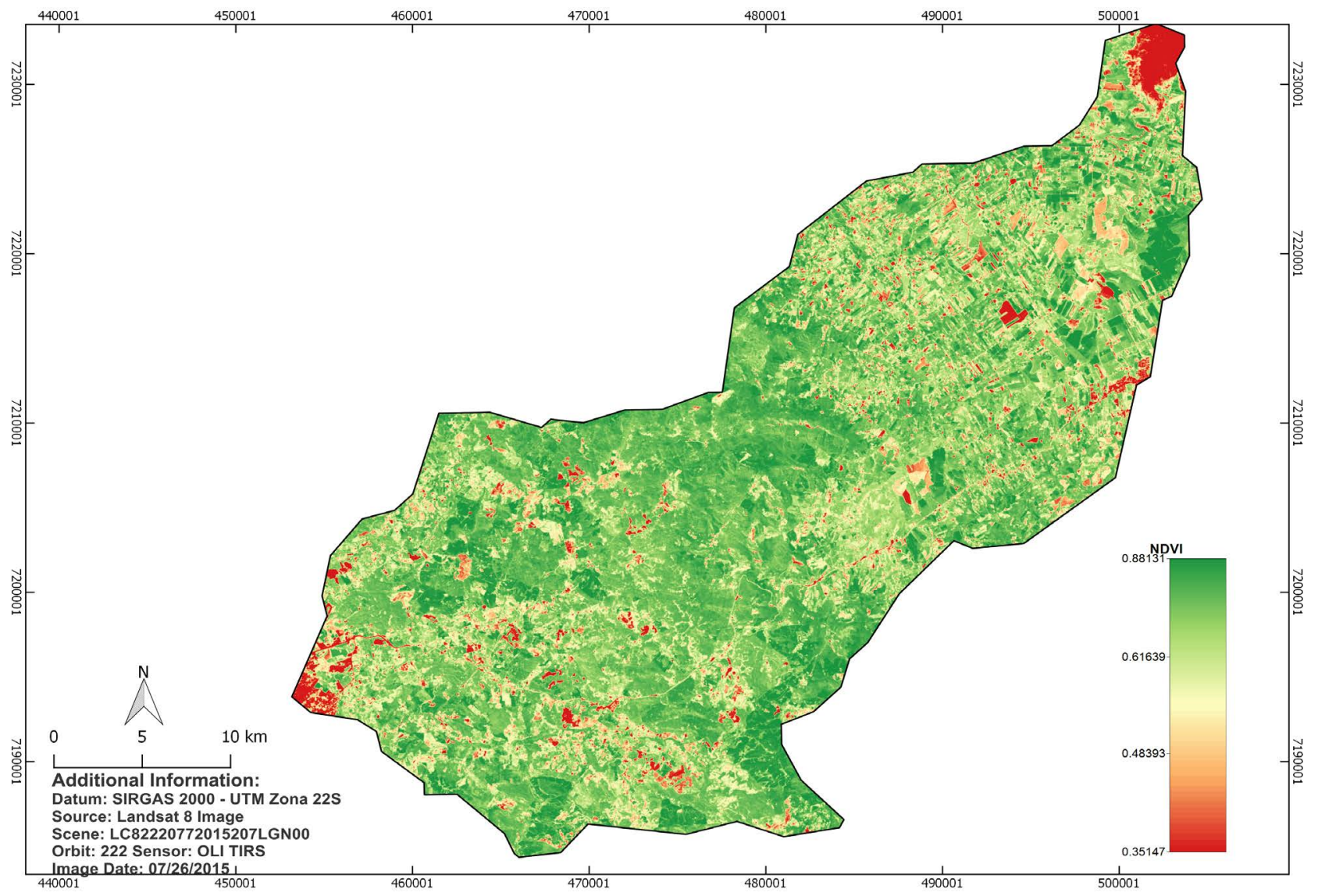

Figure 5. Spatialization of the NDVI on July 26th, 2015. 


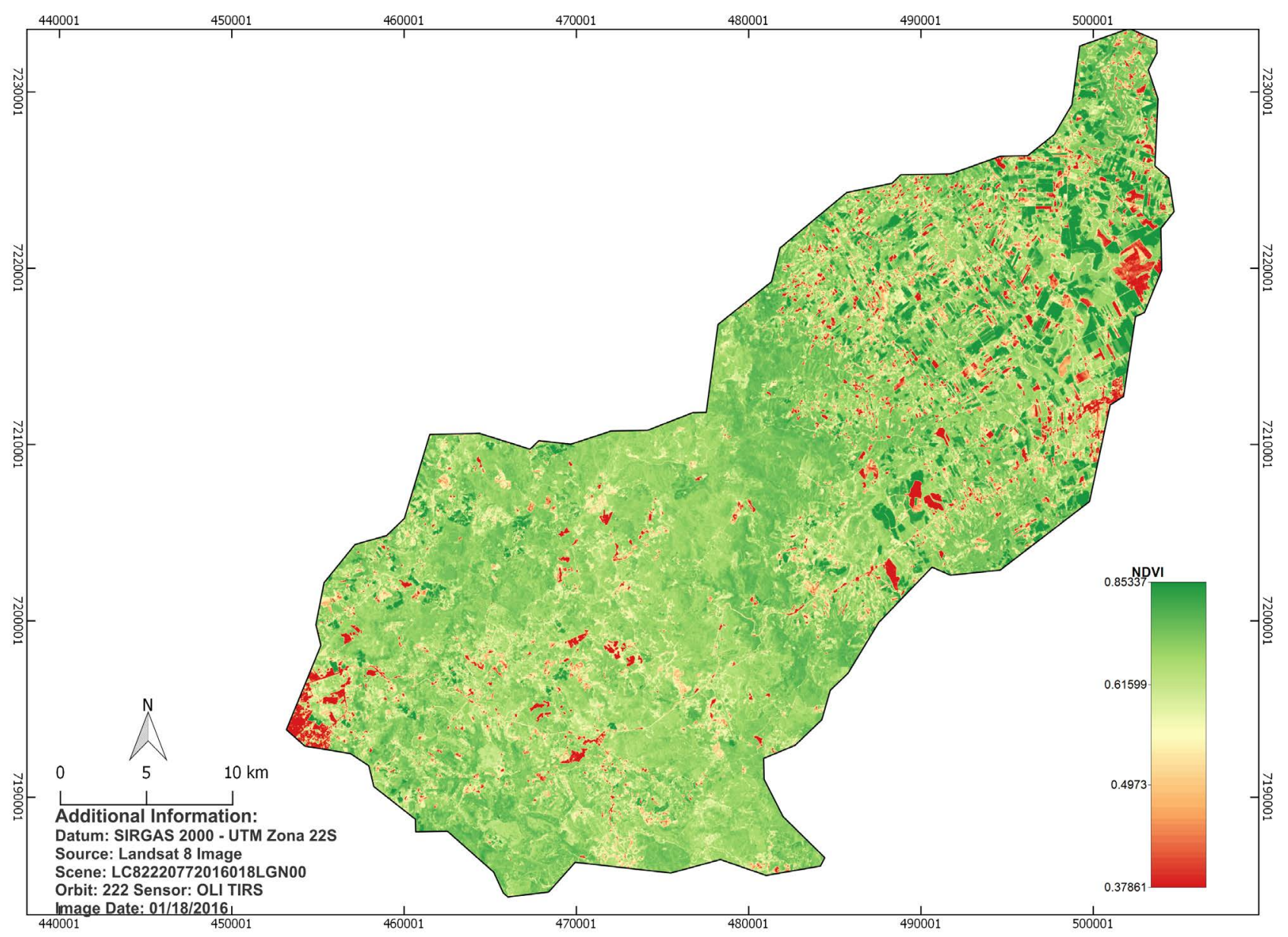

Figure 6. Spatialization of the NDVI on 18th, 2016.

The NDWI is also another analysis option to represent the relationship of land-use with climatic characteristics, since it highlights water bodies and decreases the influence of the soil in the process of deduction of air and surface temperature. Figure 7 and Figure 8 represent the calculation of the NDWI for the study area on the two selected days, in which case a greater difference between the two figures can be seen.

By analysing the NDWI calculation for winter (Figure 7) and summer (Figure 8) it is possible to identify that the potentially more heated areas do not change significantly. However, areas that indicate lower temperatures are much more significant during the summer. This is explained by the fact that urbanized areas with exposed soil (warmer) remain stable, while the moisture content in forested and arable areas increases in summer, especially in January, which is the month of that season with the highest rainfall concentration. This indicates that the humidified environments, which respond best to this index, are permanent and define possible spatial variations in air temperature and humidity for the study region.

In this case it should be noted that both in winter and summer, areas with possibly milder temperatures predominate. Even if a pattern of higher tempera- 
tures (mainly in summer) can be deduced for the extremities of the region (northeast and southwest portions) a relative homogeneity occurs throughout the study region.

Figure 9 demonstrates the spatialization of temperature values estimated by the methodology proposed by [2]. The data indicated in the sample points are the medians of the absolute values collected in loco. From these data the interpolation for the rest of the study area was made.

The hottest region at the northern end of the map is neither sample values nor interpolated, as it is the shadow of a cloudy area that appears in the Landsat image used for the interpolation process. The rest of the area has not suffered this kind of interference and it can be deduced that the data found must represent the real values according to the methodology used.

With a close look at the cartograms in Figure 7 and Figure 8, it clearly sees a relationship of air temperature spatialization according to altitude and vegetation. The higher areas (southwest), regardless the time of the year, have lower temperatures, while the area to the northeast always has higher temperatures. From April to September (Autumn and winter) it is possible to notice a slight warming in the most extreme portion of the southwest. This is explained by the

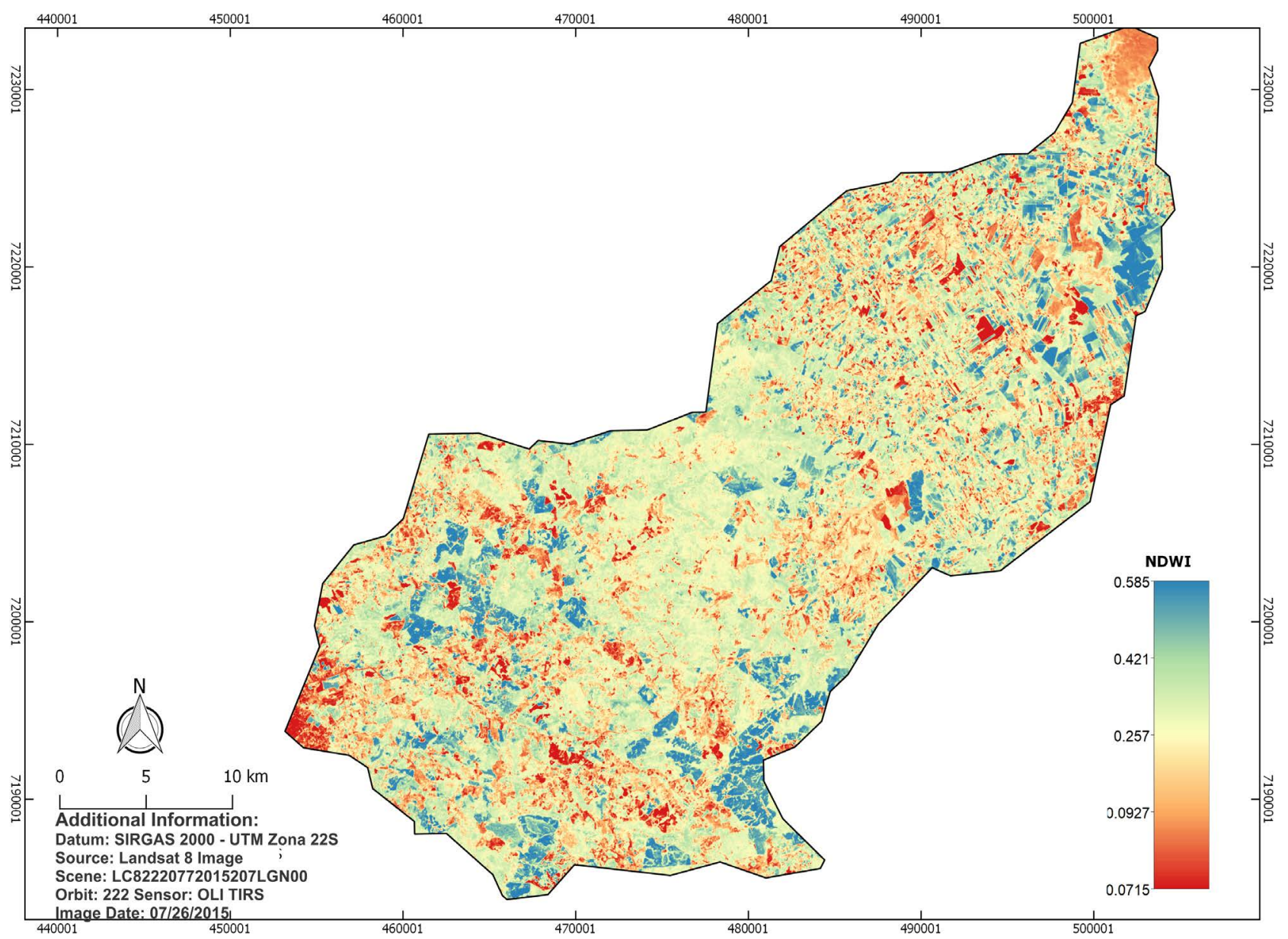

Figure 7. Spatialization of the NDWI on July 26th, 2015. 


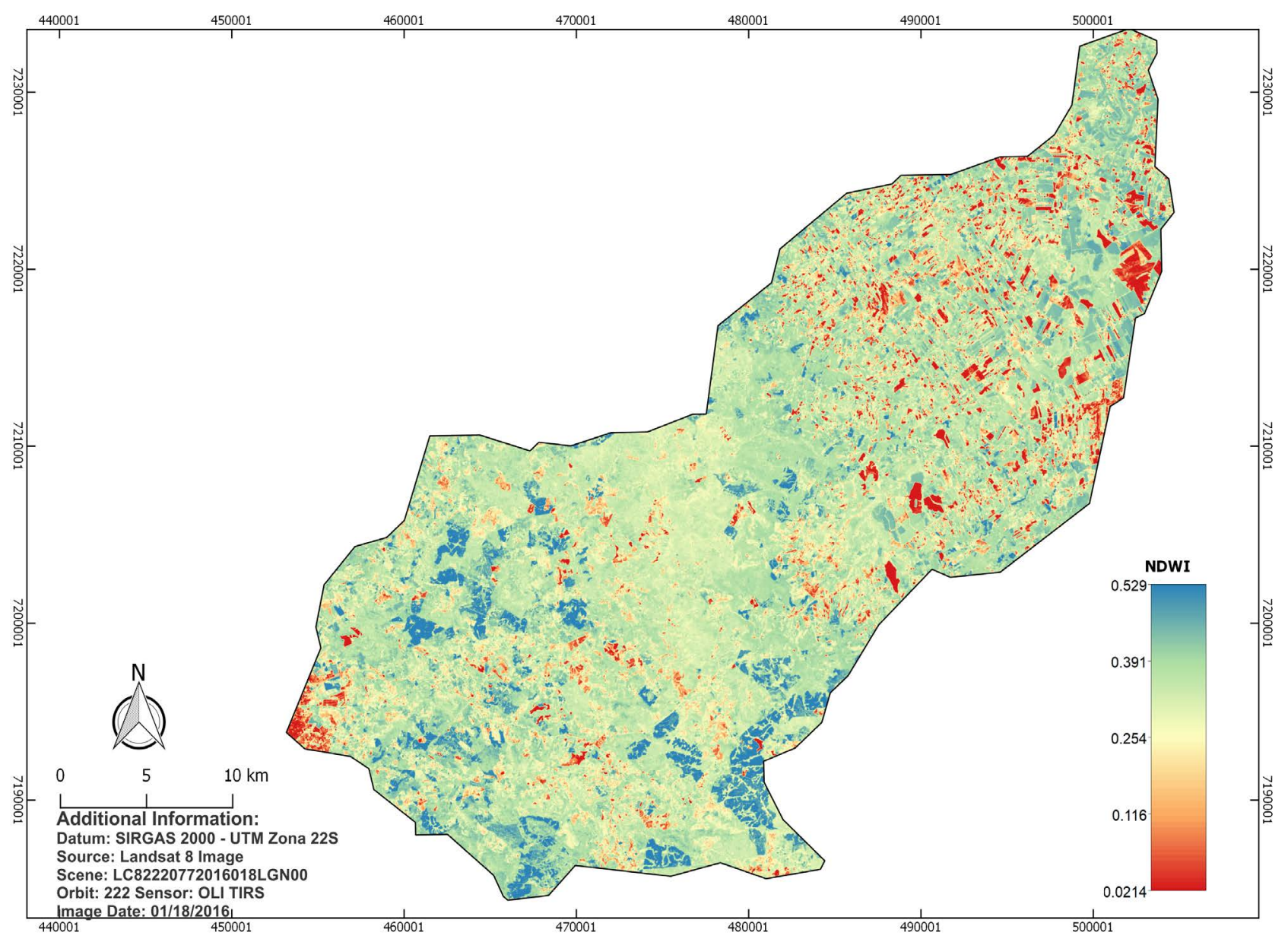

Figure 8. Spatialization of the NDWI on 18th, 2016.

proximity to the Guarapuava urban área, consequently there is a decrease in vegetation and humidity, especially at this time of the year when rainfall also decreases in the study region.

Figure 10, in turn, represents the same methodology applied in Figure 9, however, minimum temperature values are used as a database. Except for the fact that the high seasonal range, i.e., the minimum temperatures are well below the maximums obtained. So July is a good example, since the minimum temperatures are close to $9^{\circ} \mathrm{C}$, while the maximum temperatures are above $18^{\circ} \mathrm{C}$. Apart from this observation, the spatial distribution of the temperature follows the same pattern, that is, the temperatures increase as the altitude and vegetation density decrease.

Both Figure 9 and Figure 10 show the undeniable relationship between relief, vegetation and air temperature. Although land use analyses and their indices (Figure 3 to Figure 8) have highlighted a certain homogeneity for these attributes, the little existing variation, associated with the altimetry plane, is associated with air temperature monitoring and inferred by the methodology used [2].

The analysis of Figure 5 to Figure 10 allow us to identify a similarity in the spatial distribution in the NDVI results (Figure 5 and Figure 6), the NDWI 
(Figure 7 and Figure 8) and the probabilistic interpolation for maximum (Figure 9) and minimum (Figure 10) temperatures. This analogy, however, does not define arguments to affirm that this occurs in a linear manner throughout the study area, since statistical correlation cannot be approached in the analysis of these figures.
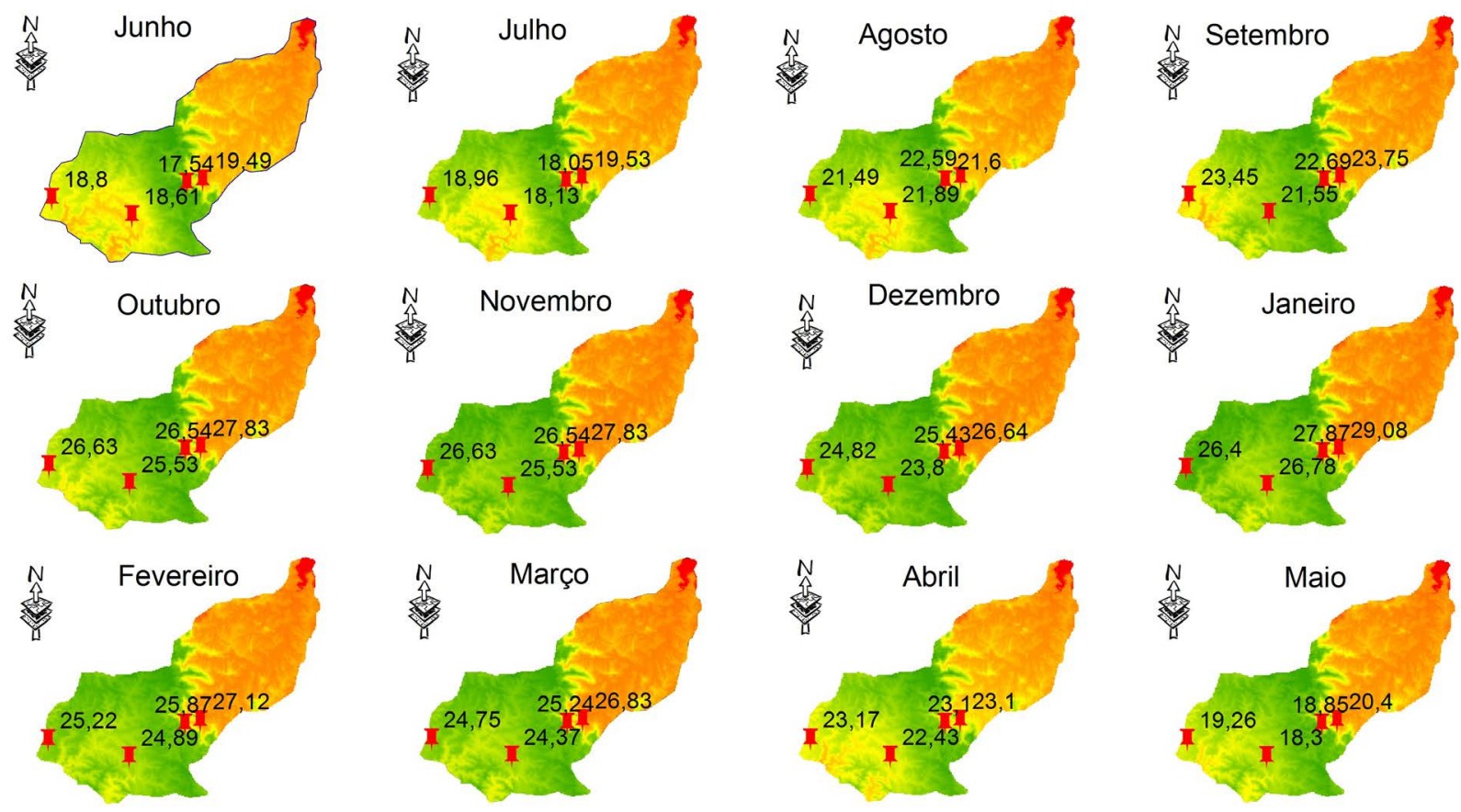

Figure 9. Spatialization of the maximum air temperature for the study area from June 2014 to May 2015.

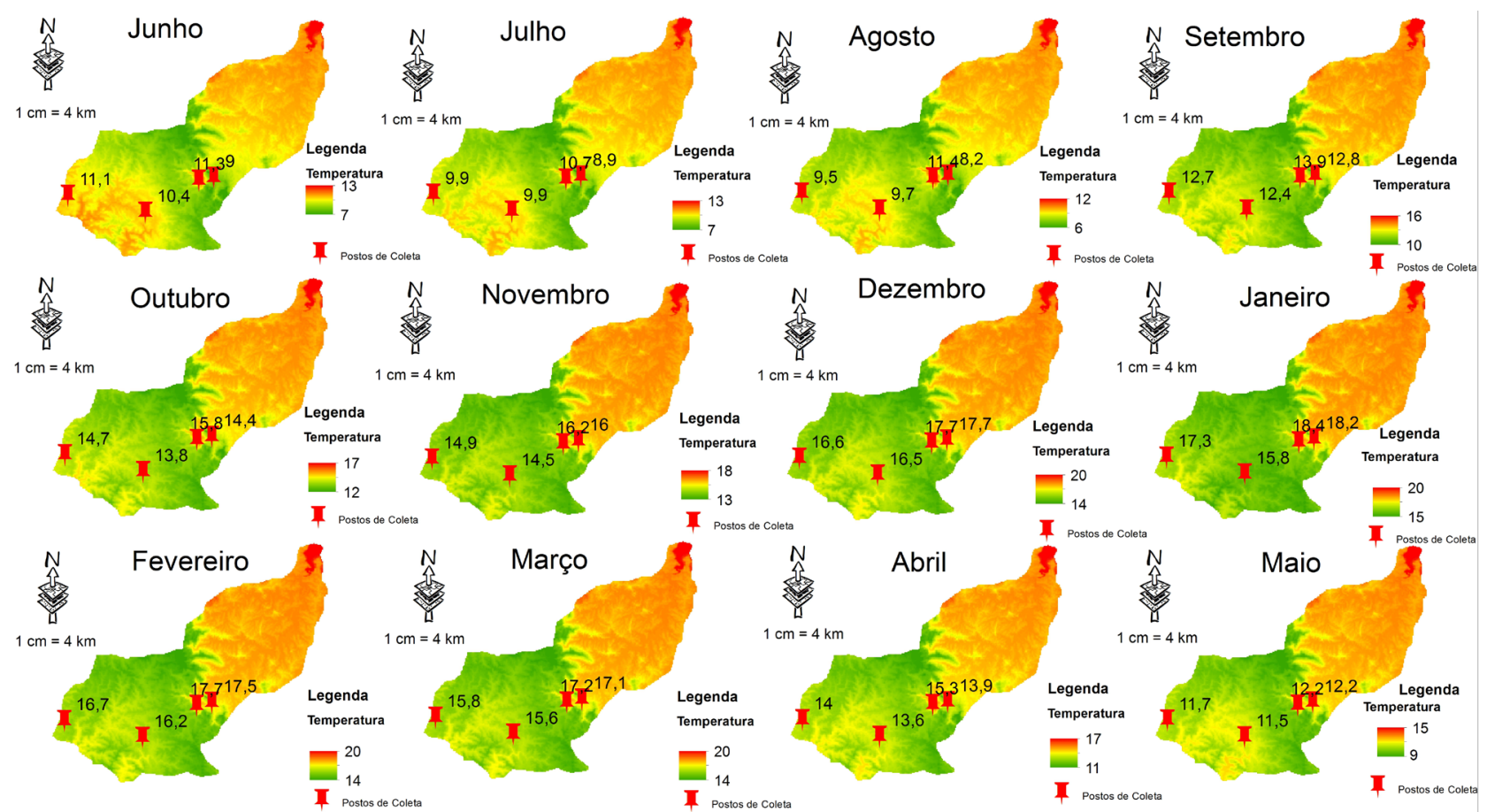

Figure 10. Spatialization of the minimum air temperature for the study area from June 2014 to May 2015. 
In search of a mathematical proof for this relationship or correlation, Geographically Weighted Regression (GWR) was carried out from 10,000 points. After the results, the GWR model was verified from the global $r^{2}$, adjusted $r^{2}$, sigma (standard deviation) and the residual sum of squares (Figure 11).

The analysis of Figure 11 clearly shows that there is a good statistical correlation between the results obtained, confirming that the methodology proposed by [2] allows the deduction of air temperature for inaccessible sites, and is precisely associated with land-use, especially with the higher or lower concentration of vegetation and surface water.

The general spatial and non-linear correlation for the study area is very good (adjusted $\mathrm{r}^{2}=0.9919$ for NDVI/TEMP MAX; 0.8879 for NDVI/TEMP MIN; 0.9919 for NDWI/TEMP MAX; and 0.9721 for NDWI/TEMP MIN) as seen in Figures 11(A)-(C) and Figure 11(D).
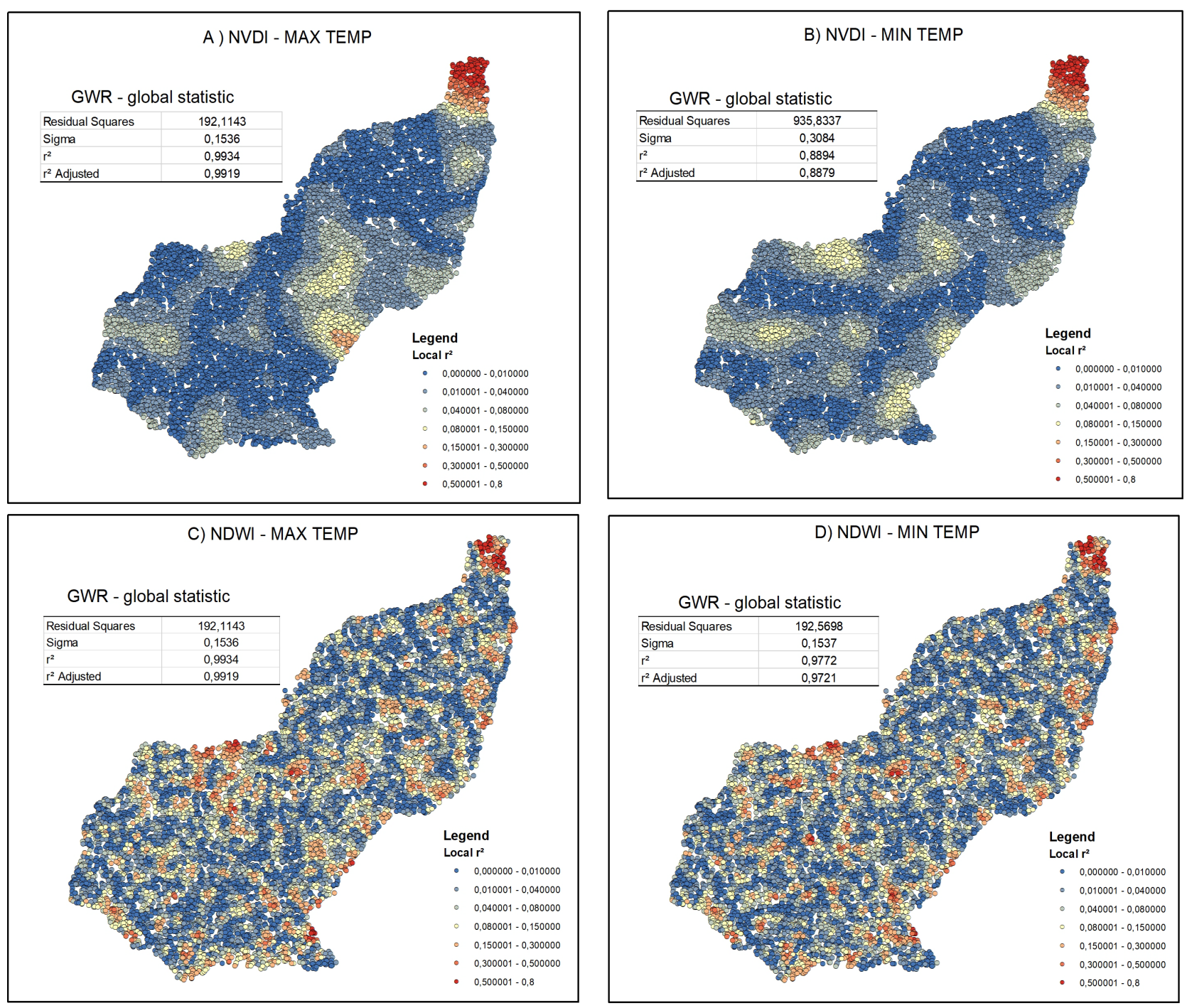

Figure 11. Correlation between the results obtained by NDVI/Maximum Temperature (A); NDVI/Minimum Temperature (B); NDWI/Maximum Temperature (C); and NDWI/Minimum Temperature (D). 
Despite this good correlation, this is the overall outcome, but there is a high spatial variability and it differs according to the type of evaluated index. Figure 11(A) and Figure 11(B), indicate that NDVI has a good correlation in the central and northern sectors of the study area, but decreases significantly in other regions. On the other hand in Figure 11(C) and Figure 11(D), which evaluate the NDWI, this correlation is much better and although it is also more significant in the central and northern parts, there are several other regions with a good correlation (over 70\%).

Thus, the technique proposed by [2], Figure 9 and Figure 10, is proven to be efficient to deduct air temperature values in regions that have no surface monitoring points, These forecasts are also associated with areas alongside greater or lesser presence of natural resources (vegetation and water).

\section{Conclusions}

The central hypothesis of this work focused on the importance of using remote sensing and geoprocessing techniques for climate assessment in hard-to-reach regions.

In permanent preservation areas, especially those associated with relief (mountains, plateaus, etc.) and endemic (native) vegetation, there are usually not many places with the possibility of monitoring air temperature. In some cases there are pluviometric stations, but thermometers that periodically collect the temperature and humidity of the air are almost not found in these areas. This is why geoprocessing techniques are useful, as they can extrapolate (estimate) data of this kind beyond a few collection points.

Thus, the present work has shown that it is possible to associate land-use (vegetation), relief (altimetry) and climate (air temperature) for the permanent preservation area of Serra da Esperança. In this way, this methodology is not only effective for estimating temperature data in places of difficult access, but can also to set levels of preservation in space and time.

Furthermore, in a conservation area, if the air temperature is rising, it can be assumed that the vegetation is decreasing. Therefore, by applying the model proposed by [2] and monitoring a few collection points, it is possible to control the evolution of this process, i.e. whether the area is really being preserved or not.

If no relation is found between vegetation and water, with the spatial variability of air temperature when remote sensing techniques and the methodology of [2] are used, it is presumed that is occurring some kind of environmental deterioration (deforestation or decrease of watercourses).

\section{Conflicts of Interest}

The authors declare no conflicts of interest regarding the publication of this paper.

\section{References}

[1] Caracristi, I. (2003) Geografia e Representações Gráficas: Uma breve abordagem 
crítica e os novos desafios técnico-metodológicos perpassando pela climatologia. RevistaBrasileira de Cartografia, 55, 15-24.

[2] Fries, A., Rollenbeck, R., Nauß, T., Petersd, T. and Bendixb, J. (2012) Near Surface Air Humidity in a Megadiverse Andean Mountain Ecosystem of Southern Ecuador and Its Regionalization. Agricultural and Forest Meteorology, 152, 17-30. https://doi.org/10.1016/j.agrformet.2011.08.004

[3] Marcussi, A.B., Bueno, C.R.P., Miqueloni, D.P. and Arraes, C.L. (2010) Utilização de Índices de Vegetaçãoparaos Sistemas de Informação Geográfica. Caminhos de Geografia, 11, 41-53.

[4] França, A.F., Tavares Júnior, J.R. and Moreira Filho, J.C.C. (2012) Índices NDVI, NDWI e NDBI como Ferramentasao Mapeamento Temático do Entorno da Lagoa Olhod'água, emJaboatão dos Guararapes-PE. Proceedings of the IV Brazilian Symposium on Geodetic Sciences and Geoinformation Technologies, Recife, 6-9 May 2012, 1-9.

[5] Molina, G.Z. and Albarran, A.J. (2013) Análisis Multitemporal y de la Estructura Horizontal de la Cobertura de la Tierra: Parque Nacional Yacambú, Estado Lara, Venezuela. Cuadernos de Geografía-Revista Colombiana de Geografía, 22, 25-40. https://doi.org/10.15446/rcdg.v22n1.36305

[6] Oliveira-Filho, A.T. and Fontes, M.A.L. (2000) Patterns of Floristic Differentiation among Atlantic Forests in Southeastern Brazil and the Influence of Climate. Biotropica-The Scientific Journal of the ATBC, 32, 793-810. https://doi.org/10.1111/j.1744-7429.2000.tb00619.x

[7] Becerra, J.A.B., Shimabukuro, Y.E. and Alvalá, R.C.S. (2009) Relationship between Vegetation Seasonal Pattern and Precipitation in the Cerrado Region by Spectral Vegetation Indexes. Revista Brasileira de Meteorologia, 24, 125-134. https://doi.org/10.1590/S0102-77862009000200002

[8] Higuhi, P., Da Silva, A.C., Budke, J.C., Mantovani, A., Bortoluzzi, R.L.C. and Ziger, A.A. (2013) Influence of Climate and Migration Routes of Tree Species on the Phytogeography Patterns of Forests in Southern Brazil. Ciência Florestal, 23, 539-553. https://doi.org/10.5902/1980509812338

[9] Albuquerque, M.M. and Lopes, W.G.R. (2016) Influence of Vegetation in Variable Climate: Sudy in Quarters of Teresina City, Piauí. Revista RA'E GA, 36, 38-68. https://doi.org/10.5380/raega.v36i0.39719

[10] Costa, C. and Andrade, A.R. (2015) Genesis and Evolution of Absolute Minimum Temperatures in the Central Southern Region of Paraná State: Influence of Atmospheric Dynamics and Local Relief. Boletim Goiano de Geografia, 35, 452-471.

[11] Silva, J.M.F. and Oka-Fiori, C. (2017) Qualitative Assessment of Potential Geomorphosites in Environmental Protection Area of Serra da Esperança, Parana State, Brazil. Caderno de Geografia, 27, 824-839. https://doi.org/10.5752/p.2318-2962.2017v27n51p824

[12] Borodiak, J., Andrade, A.R., Costa, C. and Bereze, J. (2017) Relação da Precipitação Pluviométrica e Ação Antrópica com os Deslizamentos de Terra Ocorridosna Escarpa da Serra da Esperança: Evento de 29 de setembro de 2014. Proceedings of the 17 th Brazilian Symposium on Applied Physical Geography, Campinas, 28 June-2 July 2017, 2274-2279. https://doi.org/10.20396/sbgfa.v1i2017.2471

[13] Wheeler, D. and Tiefelsdorf, M. (2005) Multicollinearity and Correlation among Local Regression Coefficients in Geographically Weighted Regression. Journal of Geographical Systems, 7, 161-187. https://doi.org/10.1007/s10109-005-0155-6

[14] Matthews, S.A. and Yang, T.-C. (2012) Mapping the Results of Local Statistics. De- 
mographic Research, 26, 151-166. https://doi.org/10.4054/DemRes.2012.26.6

[15] Neumann, C.M. (2017) Relação entre o Uso e Ocupação Terra e a Variabilidade da Precipitação e da Temperatura do Ar, no Município de Turvo-Paraná. Dissertation (Master in Geography), UniversidadeEstadual do Centro-Oeste, Guarapuava, 112 p.

[16] Amorim, M.C.C.T., Dubreuil, V. and Cardoso, R.S. (2015) Modeling Space of Urban Heat Island in Presidente Prudente (Sp)-Brazil. Brazilian Journal of Climatology, 16, 29-45. https://doi.org/10.5380/abclima.v16i0.40585 